\title{
Workplace productivity and bonus preferences; why do men with low productivity prefer individual pay?*
}

\author{
Gaute Torsvik ${ }^{\dagger}$
}

April 2015

\begin{abstract}
This paper examines how workers' productivity and risk aversion relates to their preferred bonus scheme (team or individual). The data is from a company where agents work in teams and receive a bonus that depends both on individual and team performance. If workers care mainly about their own income, those performing below the team average should go for a team bonus, while those with a productivity above average should vote for an individual bonus. Risk aversion may moderate the taste for individual pay. I find that the standard model predicts the observed relationship between productivity and bonus preferences fairly well. There is, however, one noticeable pattern it cannot explain; many low performers - especially men prefer individual bonuses.
\end{abstract}

JEL-Code: J33, J41, L23, D630

Keywords: payment systems, team incentives, social appraisal, fairness.

\footnotetext{
*I thank Karl Ove Aarbu, Edwin Leuven, Fred Shroyen, Tore Ellingsen, Andreas Kotsadam, Matthias Sutter, Ola Kvaløy, Bertil Tungodden, Ottar Mæstad, Sara Cools and Robert Dur for helpful suggestions. I also thank the editor of this journal and an anonymous referee for their constructive comments.

†University of Oslo: gaute.torsvik@econ.uio.no
} 


\section{Introduction}

This paper reports survey evidence from employees at an inbound call centre of an insurance company, concerning their preferred bonus scheme. Workers were asked whether they wanted a scheme based on individual performance, or one based on team performance. The data set has two important virtues. First, the surveys, conducted in 2007, 2009 and 2010 constitute a panel, where the workers express preferences over wage contracts they are familiar with. In the firm, agents work in teams with $8-12$ members, and performance pay make up a non-trivial part of their renumeration. On several occasions they have voted for either an individual- or a team-based bonus scheme. Second, the data on bonus preferences are matched with participants' actual work performance and other worker characteristics, including elicited measures of risk aversion.

While interesting in itself, an examination of how workers' preferred bonus scheme relate to their relative workplace productivity can also shed light on the strength and composition of social motivations at a workplace. These motivations matter for the optimal design of monetary incentives. ${ }^{1}$ Despite its importance for the organization of economic activities and the design of monetary incentives, there are relatively few empirical studies assessing the relevance of social motivations at real workplaces. ${ }^{2}$ This paper contributes to that limited literature.

If workers focus only on their own earnings and effort costs, as in the standard Principal-Agent model, those who perform consistently better than the team average prefer individual pay, while those performing below average prefer a team bonus. Risk aversion may change this pattern. Team pay reduces the variability of bonus payments and some risk averse high productivity agents may therefore prefer a team bonus. The

\footnotetext{
${ }^{1}$ Workers with strong social ties will, for example, work harder under a piece rate than in a tournament (Bandiera et al., 2005). Workers with a preference for equal pay may produce more under a team bonus than with individual bonuses (Itoh, 2004, Rey-Biel, 2008 and Englmaier and Wambach, 2010). Team incentives may also bring on social appraisal concerns, like the fear of social punishment or the desire of being liked and admired, which can amplify the power of monetary incentives (Hamilton et al., 2003 and Babcock et al., 2011). Team pay encourages socially oriented workers to use time and energy to strengthen ties (create altruism) within production teams to alleviate free rider problems (Dur and Sol, 2010).

${ }^{2}$ There are some recent studies that use field data to assess how social concerns affect worker behavior. Bandiera et al., 2005 and Mas and Moretti (2009) are two prominent examples; others are reviewed in List and Rasul (2011).
} 
Principal-Agent assumption that workers make choices to maximize their own income has, however, been challenged by recent lab experiments where participants display non-selfish behavior, indicating a range of social, cooperative motivations, such as inequity aversion, altruism and guilt.

Workers who are inequity averse have utility functions that increase in their own income, but decrease in the level of income inequality, as in Fehr and Schmidt (1999). If inequity aversion is an important concern, we should expect a leaning towards team pay (compared to the Principal-Agent model). Low productivity workers, who do not like inequity, have two reasons for preferring a team bonus, while workers with high relative productivity face a trade-off between own income and equal pay within the team. If, however, the relevant social concern is to avoid negative appraisal from team mates we should observe a bias towards individual pay. Low productivity workers may prefer individual pay in order to avert the negative social appraisal and peer pressure that comes from the fact that they drag down the pay of other team members.

A one-line report on the findings of this study, would conclude that the Principal-Agent model explains the workers' bonus preferences very well. In the data there is a strong positive association between relative productivity and a preference for an individual bonus. This result holds also when estimated with individual fixed effects (exploiting the panels structure of the data). Furthermore, risk aversion is associated with a preference for a team bonus, also in accordance with the standard economic Principal-Agent model. I find that men are more drawn towards individual pay than women are. This is in line with the results in Kuhn and Villeval (2015) where, in a lab experiment, they find that women choose team-based pay more frequently than men. Controlling for productivity and risk-aversion I find no evidence that age, tenure or education (having an economics or business degree for example) of the employees matter for their bonus preferences.

There is, however, one pattern in the data that is not in accordance with that model: A high fraction of low productivity workers, especially men, prefers a bonus based on individual productivity. This pattern does not only deviate from income maximizing behavior, it is also in direct conflict with the inequity aversion hypothesis. The observed 
pattern indicates that workers are equity averse, rather than inequity averse.

Lack of information about own productivity (over-confidence), and a prospect of upward mobility in the productivity hierarchy within a team, are two possible explanations for why workers who perform below the team average prefer individual pay. The data does not lend much support to these hypotheses. Another possibility is that agents with a very strong taste for individual pay do not produce up to their capacity as long as there is an element of team pay in the bonus scheme (they are free-riders). Although the causality could go this way, I argue it is unlikely. At the time of the surveys, the maximal individual bonus was almost three times as high as the maximal team bonus, making it very costly for high productivity workers to free-ride (see Figure 1 for an illustration of the payment plan). To further check this possibility, I exploit a short window (6 months) when the bonus was based solely on individual productivity. If the free-rider explanation makes sense, we should observe that the low productivity workers who prefer individual pay should excel in this period. They do not.

This leaves us with two obvious explanations for why a relativly high fraction of low productivity workers prefer individual pay. They may find individual pay fair, or they may want individual pay in order to rid themselves from the negative emotions and peer pressure they experience when they are reminded that they are below average. While there is no direct evidence for the social appraisal mechanism, it is the explanation that is not refuted by the data. It is also consistent with other indications that workers seem to stretch quite a bit in order to avoid letting down their team (Babcock et al. (2011); Hansen (1997)), and with the finding in Weiss (1987) that a high fraction of the low productivity workers left a firm that went from individual to team pay.

\section{Contribution and relation to the literature}

There is a large literature on teams and work groups in psychology, organization theory and economics, but not much is written on the factors that influence workers preferred bonus scheme and whether it should be based on team production or individual production. Our knowledge on this issue is mostly based on lab experiments where participants 
can, under different circumstances, sort into different remuneration schemes; Dohmen and Falk (2011) and Kuhn and Villeval (2015) are two recent examples of this research. In Kuhn and Villeval (2015) participants can choose to work in a two-person group and share the value that is created, or they can opt for individual production. These authors are especially interested in whether, and why, there are gender differences in the choice of teamwork. This is an issue addressed also in the present paper. Since I am studying work groups within a real firm, where agents operate together in closely knitted work groups for a long time, it is likely that concerns (status and peer pressure for example) will arise here that are not relevant in the lab experiments referred to above, where teams are composed of "workers" who interact briefly and never actually see each other. In this respect the results presented in this study can complement the experimental research on sorting into team production.

When workers know their own relative productivity and free-riding is not an important problem, as I shall argue is the case in the customer service centre, the choice between team and individual pay is essentially a choice of how to divide income within a group. How individuals share money between themselves and others have been studied extensively in the lab over the last two decades. The research question addressed in this paper relates to this literature.

The simplest sharing experiment is the Dictator Game. Results from this game, and from its cousins (for example return decisions in a Trust Game), reveal that many individuals are willing to share their money in controlled laboratory experiments, see Camerer (2003) and Cooper and Kagel (2009)for a general discussion of what these games can tell us about individuals other regarding preferences. A major difference between a standard Dictator Game and the case at hand is that when team members express their preference over bonus schemes, the amount they "divide" does not fall into their hands as manna from heaven. The sum to be divided is produced by the team members. There are lab experiments on sharing where individuals produce/invest before they divide the value that is created (see Cappelen et al. (2007) and Konow (2003) for references).

Compared to the studies of production and sharing in the lab, this study has advan- 
tages and drawbacks. Again, the production phase is clearly more relevant here than in real effort lab experiments, where participants typically are set to do 10 to 20 minutes of trivial task solving before they divide the proceedings. Another advantage is that the workers I study are familiar with the sharing problem they are asked to take a stand on. For many years the bonus has been based on both individual and team sales and the relative importance of team performance has varied over time. In one period team members could vote over two alternatives; a bonus with $80 \%$ weight on team sales and $20 \%$ on individual sales, or a bonus scheme with opposite weights. I think it is noteworthy that the subjects I study take a stand on a sharing problem they find relevant, and are familiar with. Participants in laboratory experiments may feel a bit baffled by the strangeness of the situation they are put in.

This is a case study, and case studies have their limitations. These data comes, however, from an important industry. The customer service business is large and fast growing. Estimates made by the Incoming Call Management Institute assess that there where 2,7 million agents working in inbound call centers in the US in 2007, and 2,1 millions in Europe, Africa and the Middle East(Aksin et al., 2007). Hence, even if this study only sheds light on the preferred bonus contracts within this particular sector it should be noted that it is an industry that employs a lot of people. In addition, some of the mechanisms I address, e.g. the role of self-interest and social preferences at a real workplace, should be of general interest.

A potential drawback of this study is that agents state their preferences over bonus schemes; their response has no, at least no immediate, financial consequence. As pointed out above, the outline of the bonus scheme - and especially whether the bonus should be based on individual or team performance - is of real concern for these workers, and workers have actually voted over this issue on several occasions. I see no reason why they should conceal their true preference in the survey. On the contrary, if they believe that the results from the study will be used to craft a new bonus scheme, they have every reason to state how they rank the alternatives.

The paper proceeds as follows. Section 2 presents the workplace and the bonus scheme. 
Section 3 contains a brief theoretical discussion of how bonus preferences are shaped by self-interest and social concerns. Section 4 describes the data on productivity, risk-aversion and bonus preferences. The results are presented in section 5 and the concluding remarks in section 6 .

\section{The workplace and the data}

\subsection{The customer service centre}

The workers in this study provide customer services through an inbound call centre. A computer based phone system automatically channels new calls to available personnel. The agents use the computer to obtain the information they need to assist customers, and to register new information in the customer database. Their main assignment is to inform existing clients about their insurance coverage, notify them if there are any relevant changes and inform them about new products that are available. All this should be done as fast as possible, in a friendly and courteous way. In addition to the service assignment, the operators sell insurance products. In fact, the customer service unit is an important sales channel in the company; approximately $30 \%$ of the company's total sales come from the customer service centre.

At the time of this study, around 140 - 150 full time customer service agents are working at the centre. The agents belong to teams consisting of one team leader and 8 - 12 customer service agents. Teams are clustered together in an open office landscape. Agents were grouped into teams not to exploit complementarities in production as work duties are to a large extent individualistic, but rather to enable an efficient system of "coaching" and to create a form of team spirit and team motivation. Agents are permanent members of one single team; over the period I have collected data ( 8 years) there is only a handful of cases where members switch from one team to another.

Agents enter a sale in the computer system when a customer agrees to buy a product. The sale is not formally registered in the database before the customer accepts the contract, which may happen two or three days after the phone call (for some products, such 
as health insurance, which requires a medical certificate, it may take much longer).

Each team has a team leader who organizes, motivates and supervises individual team members. Team leaders are employed as such, and they do not take part in the bonus scheme. At the beginning of each week, team leaders inform agents about their performance (sales) during the previous week.

\subsection{The bonus scheme}

In 2001 the firm introduced a performance bonus to increase sales in the customer service unit. The variable pay element has increased in magnitude over time; in 2001 the bonus pay amounted to (on average) 7\% of the salary, in 2010 it had increased to almost $15 \%$ of total compensation. To balance sales incentives the company has rewarded a number of variables related to the quality of the services that are provided; claims ratio, service level, efficiency (answered phones per hour logged on to the computerized phone system) and attrition rates. The sales bonus is, however, by far the most important element, it accounts for approximately $80 \%$ of the variable pay. To earn the individual sales bonus agents must sell above an assigned sales budget (which is the same for each full time agent). For sales above that level the bonus increases in steps, the number of steps and the width and hight of the steps have varied over time. The agents earn a team bonus if the team produces above its assigned budget, which is given by the sum of the individual budgets.

The initial bonus was based solely on team performance and depended on quarterly achievements. Since 2004, however, the bonus has depended on a combination of individual and team sales (except for two quarters). The weight assigned to individual performance (relative to team performance) has varied over time. In 2005/2006 the teams could decide (majority vote) whether to go for a bonus with $80 \%$ weight on team performance and $20 \%$ on individual performance or one with the opposite weights. In two quarters - the last in 2006 and the first in 2007 - the sales bonus was based solely on individual sales.

Figure 1 depicts how the maximal team and individual bonus has developed over time. 


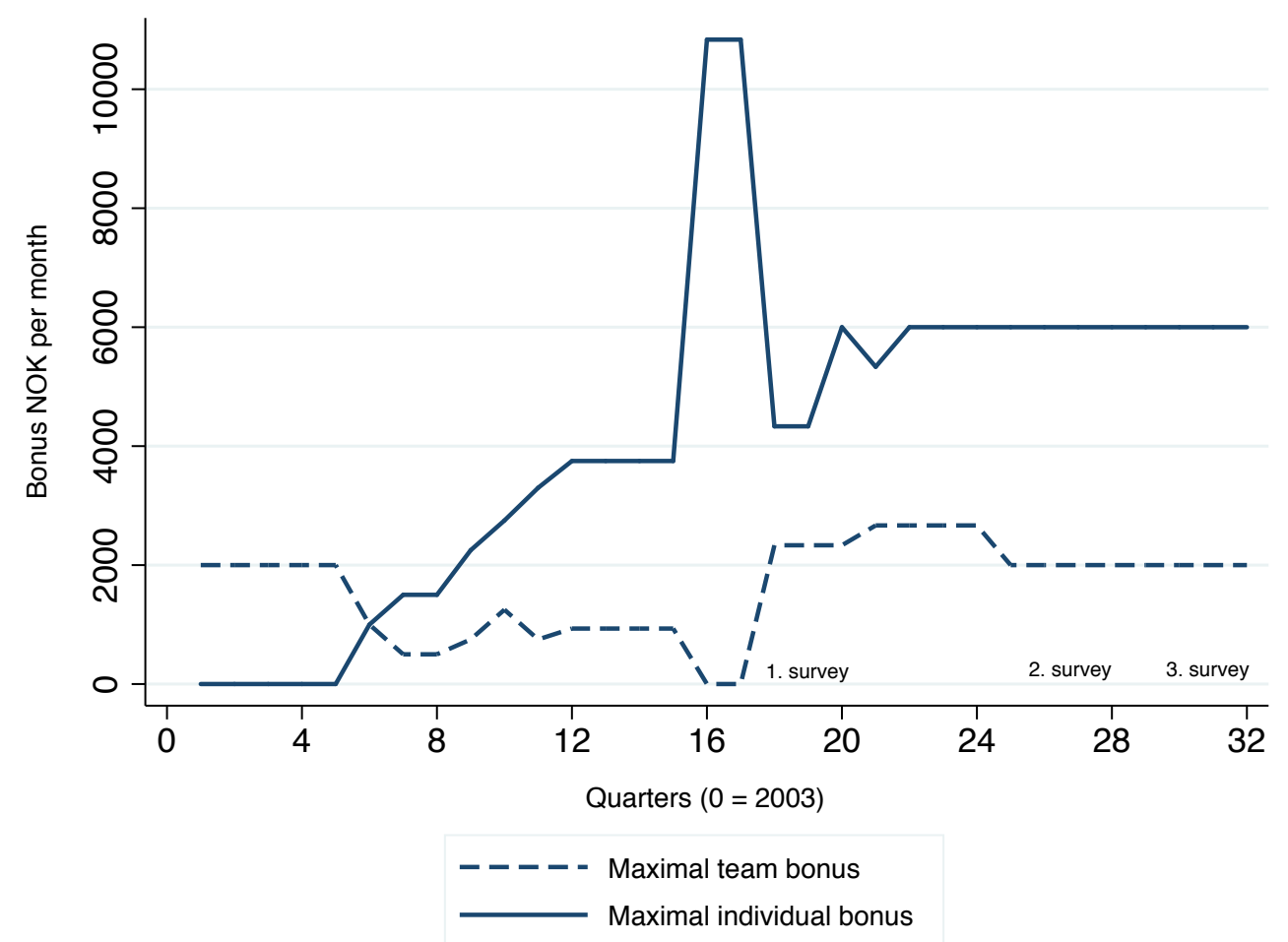

Figure 1. Maximal individual and team bonus per worker

In this . The bonus is based on monthly sales (relative to budget) but is remunerated on a quarterly basis. It is the quarterly bonus in Norwegian Krone ( $1 \mathrm{NOK} \approx \frac{1}{6}$ US Dollar) that is measured along the vertical axis in Figure 1. The maximal individual bonus is three times as high as the maximal team bonus (per worker) at the time of the surveys (a bit less in 2007).

\section{Theoretical backdrop}

The idea is to use the relationship between the agents "choice" of bonus scheme and their relative productivity to examine the strength and structure of social concerns within working teams. It is a good place for making such an inquiry. Although the agents operate in teams their work tasks are mainly individualistic (there are few complementarities between agents within teams) and the agents have accurate information about their own relative productivity within the team. In such a context, choosing between team and individual pay is essentially a choice of how to divide income within a group of workers.

Consider a team of workers where agent $i$ sells $s_{i}\left(\theta_{i}, \varepsilon_{i}\right), \theta$ is the productivity of the 
agent and $\varepsilon$ is a random variable capturing all the haphazards that affect individual sales. ${ }^{3}$ Sales increase in both arguments. In this simple exposition the productivity parameter encompasses both the talent and the effort of this person. The random variable is iid with expected value zero and a positive variance $v$. To simplify notation further assume that sales is additive in productivity and "noise": $s_{i}=\theta_{i}+\varepsilon_{i}$. An individual bonus with a bonus rate $b$ gives agent $i$ an expected pay $b \theta_{i}$, with variance $b^{2} v{ }^{4}$ A team bonus with the same bonus rate, gives expected pay $\frac{1}{n} b\left(\theta_{i}+(n-1) \bar{\theta}_{-i}\right)$, where $\bar{\theta}_{-i}$ is the average productivity of the other team members, and variance $\frac{1}{n} b^{2} v .^{5}$

\subsection{Selfish agents}

Suppose first that agents are risk-averse and selfish (as in the Principal-Agent model). Their preferences can be represented by a concave function $u($.$) defined over personal in-$ come. With this motivation, only high productivity agents face a trade-off when choosing between the two bonus alternatives. An individual bonus maximizes expected pay but also the variability in pay. For low productivity agents a team bonus is best both in terms of maximizing expected pay and minimizing bonus uncertainty.

\subsection{Social concerns}

Assume that the choices of a socially sensitive agent can be described as if he is maximizing $U_{i}=u(\cdot)-\beta_{i} v_{i}(\cdot)$, where $v(\cdot)$ is a function capturing the relevant social concerns. According to this specification, agents have a preferred social outcome and deviating from this standard inflicts a loss that is assigned a weight $\beta_{i}$.

There are two types of social considerations that may play a role for workers ${ }^{\natural}$ preferred payment system. Workers may care directly about the outcomes for their coworkers, they

\footnotetext{
${ }^{3} \mathrm{~A}$ more accurate formulation of the sales equation is $s_{i}=p\left(e_{i}, a_{i}\right) q\left(E_{i}, A_{i}\right) T$, where $T$ is the number of customers contacting the centre, $q$ is the fraction of the customers that are served by the agent, and $p$ the fraction of these customers that are buying an insurance product. $e_{i}$ and $a_{i}$ is the sales effort and talent of this agent, and $E_{i}$ and $A_{i}$ is the effort and talent the agent has for working efficiently so as to be ready for a new call as fast as possible.

${ }^{4}$ The bonus depicted in Figure 1 is piecewise (approximately) linear, but the basic trade-offs that are illustrated here extends to a non-linear bonus.

${ }^{5}$ The random component in production is likely to be positively correlated within a team. That is not taken into account here. With correlation, the variance in the bonus that each worker receives with team pay must be adjusted upwards with a covariance term.
} 
may, for example, be concerned with the fairness of pay within a team. Workers may also care in a more indirect and self-regarding way about the social appraisal, esteem and status they obtain within a work group.

\section{Distributional fairness}

The idea is that individuals adhere to a norm of distributional fairness and deviating from that standard hurts. The most influential paper within this approach is Fehr and Schmidt (1999). ${ }^{6}$ They suggest that (some) individuals are inequity averse and willing to sacrifice personal income to increase equity. To illustrate, assume for simplicity that the loss associated with a discrepancy between the actual outcome and the fairness ideal is quadratic. ${ }^{7}$ Assume agents take the bonus rate as given. For expositional reasons, we now disregard the random component in the production process $(\varepsilon=0)$. The utility of an inequity averse agent in team $J$ under an individual bonus is given by

$$
U_{i}^{I A}(I B)=u\left(b \theta_{i}\right)-\beta_{i} \sum_{j \in J}\left(b \theta_{j}-b \bar{\theta}\right)^{2}
$$

With a team bonus this agent obtains utility

$$
U_{i}^{I A}(T B)=u(b \bar{\theta})
$$

Only inequity averse agents with a higher productivity than the team average face a tradeoff; a team bonus gives maximal equity but a lower income than an individual bonus. An inequity averse agent with low productivity gets yet another reason for wanting a teambonus.

When team members express their preference over bonus schemes the amount they "divide" does not fall into their hands as manna from heaven. An equal split may not be the relevant fairness standard in a team with heterogenous production. In lab experiments where individuals produce/invest before they divide the proceeds, those contribut-

\footnotetext{
${ }^{6}$ Alternative formulations of fairness preferences can be found in Bolton and Ockenfels (2000), Charness and Rabin (2002).

${ }^{7}$ In the Fehr and Schmidt (1999) model the trade-off is linear and the costs of inequity depend on whether an individual gets more or less than the average.
} 
ing more tend to claim, and being granted, a larger share of the pie (Cappelen et al., 2007 and Esarey et al., 2012). This behavior is consistent with meritocratic fairness preferences where distributional fairness is conditioned on individual effort and achievements ((Konow, 2003; Cappelen et al., 2007). ${ }^{8}$

A meritocratic agent prefers a scheme that gives individual workers a pay proportional to their production. Such an agent obtains utility

$$
U_{i}^{M}(I B)=u\left(b \theta_{i}\right)
$$

if the bonus is based on individual production, and utility

$$
U_{i}^{M}(T B)=u(b \bar{\theta})-\beta_{i} \sum_{j \in J}\left(b \theta_{j}-b \bar{\theta}\right)^{2}
$$

if the bonus is team based. Hence, if workers possess a meritocratic fairness standard, it is the low productivity agents who are facing a trade-off between own pay and fairness. By comparing $U_{i}^{M}(I B)$ and $U_{i}^{M}(T B)$ we can see that a meritocratic and sufficiently fair minded (high $\beta$ ) low productivity agent will vote for an individual bonus.

\section{Social appraisal}

Another line of the research on human sociality and economic behavior is less cerebral. It presumes that workers care about the respect and admiration they get from colleagues and supervisors. Social appraisal concerns are accentuated by a team based bonus. Babcock et al. (2011) argue, and provide experimental evidence, that individuals obtain disutility from letting down their team. To avoid negative self and social appraisal (and the guilt and shame that follows) low productivity workers may prefer individual pay. Kandel and Lazear (1992) examine theoretically how peer pressure can curb free

\footnotetext{
${ }^{8}$ Fershtman et al. (2012) introduce a competition twist in a Dictator Game and show that this induce many of the participants to choose an unequal split of the money that is to be divided. The dictator and the recipient solve a task and their payoffs depend on their relative performance. If the dictator outperforms the recipient, he gets 11 dollar and the recipient gets 2 . If the recipient outperforms the dictator, both gets 8 dollar. It is easy for the dictator to guarantee an equal split as it is permissible to leave the task unsolved. Very few do. The authors suggest that by engaging in the competition dictators can appeal a "meritocratic" fairness norm which supports an unequal split of the resources.
} 
riding within teams. Peer pressure and lack of respect may induce workers with a low innate productivity to vote for individual pay, even if that means they get a lower income.

Formally, we capture workers' social appraisal concern by letting the utility loss of a low productivity worker $\left(\theta_{i}<\theta\right)$ increase in the distance to the team average;

$$
U_{i}^{S A}(T B)=u(b \bar{\theta})-\beta_{i}\left(\theta_{i}-\bar{\theta}\right)^{2}
$$

A person with above average productivity may get an appraisal reward if working under a team based bonus scheme (but there is not necessarily a symmetry here). As an individual bonus removes any income externalities within teams it does not - at least not to the same extent - raise social appraisal concerns. Hence an individual bonus gives a low productivity agent utility

$$
U_{i}^{S A}(I B)=u\left(b \theta_{i}\right)
$$

Although there is an overlap between the two types of social concerns (fairness and social esteem), they are of a distinct nature. To see this, and the importance of keeping them apart, suppose a low productivity worker was asked, as an impartial spectator, how pay ought to be divided within a team; on an equal basis or in proportion to individual production. Suppose she adheres to an egalitarian fairness principle. It is not inconsistent, perhaps not even surprising, if this person as a partial team member prefers an individual bonus scheme. She is voting against her material self-interests and her fairness standard; she prefers individual pay to avoid negative social appraisal from lowering the bonus of team-mates.

\subsection{Social concerns and bonus preferences}

In a gradual and probabilistic world the standard Principal-Agent model predicts a positive relationship between agents' expressed preference for an individual bonus and their relative productivity within the team. A high risk aversion may induce some agents with a relative high productivity to prefer a team bonus. If we observe patterns that are inconsistent with this prediction it could be because workers have social motivations. 
It is difficult to separate the role fairness concerns have on bonus preferences from the impact of social esteem. Suppose, as an anticipation of the results presented later, that many low productivity agents prefer an individual bonus. This pattern is consistent with workers holding meritocratic fairness standards triumphing their material self-interests. It is also consistent with low productivity workers trying to avoid the peer pressure and negative social esteem that comes with a team based bonus.

Even though a meritocratic fairness standard and a desire to avoid negative social appraisal both predict a push towards individual pay, there is one difference that can be used to separate these motives. The utility loss a meritocratic person gets by working under a team bonus $\left(U_{i}^{M}(T B)\right)$ increases in the variance of production within the team. The more agents differ in productivity within a team the more will a meritocratic person suffer under a team bonus. Heterogeneity within the team does not, per se, affect the loss a low productivity person suffers from negative social appraisal. This utility $\left(U_{i}^{S A}(T B)\right)$ depends mainly on the gap between own productivity and average productivity within the team.

\section{The Data}

The data come from three different sources. The information on individual worker characteristics, age, gender, sickness absence, number of children etc. are from personnel files in the firm. Individual data on workplace performance; logon hours, number of answered phones, number of insurance units sold etc. are gathered from the computer system agents use to serve the customers. The information on preferred bonus schemes and attitudes towards income uncertainty (risk aversion) is collected through three surveys.

\section{The surveys}

The surveys were conducted in 2007, 2009 and 2010, all in the fall as shown in Figure 1. The last two surveys were web-based and distributed via the agents' work email. The survey conducted in 2007 was paper-based and was distributed and returned by standard mail. At any time around 15 to $20 \%$ of the agents are absent from the customer 
service centre; they participate in courses, do back-office work or are away due to sickness absence, maternity leave, etc. In addition, the surveys were only sent to agents who had been employed for more than three months. The response rate for the last two surveys were just below 70\%; the initial 2007-survey had a lower response rate, around $50 \%$.

Agents answered a battery of questions concerning their attitudes towards risks, preferred bonus design, main motivation for exerting effort, team and company identification etc. To elicit bonus preferences agents were asked to respond to the following statement: "I think the bonus should be based on individual performance, not on team performance". They responded along a Likert scale, with the following alternatives "totally agree", "agree", "neither agree nor disagree", "disagree", "totally disagree". My interpretation is that agents who answer "totally agree" are strongly in favor of individual bonuses, while those who ticked of "totally disagree" are strongly in favor of a team bonus.

To get a measure of their risk attitudes, agents were asked to make a sequence of choices among two different job alternatives, one with a sure income identical to current income, the other alternative was a risky job that paid either twice the amount of the current job or only a fraction $\lambda \leq 1$ of the current salary, both outcomes being equally likely. ${ }^{9}$ The initial gamble was described as follows:

"Suppose you are the only income earner in your household and that reasons beyond your control force you to change occupation. You can choose between two alternatives. Job 1 guarantees you the same income as your current income. Job 2 gives you a $50 \%$ chance of an income twice as high as your current income, but with a 50\% chance it results in a reduction of your current income by one third. What is your immediate reaction? Would you choose job 1 or job 2?"

After having made a choice (with $\lambda=2 / 3$ ) the respondents got a new pair of alternatives. Agents, who selected the safe job in the first round, got an alternative with a higher $\lambda$

\footnotetext{
${ }^{9}$ This approach to elicit risk aversion is equivalent to the one used in Aarbu and Schroyen (2009), which builds on Barsky et al. (1997).
} 
(it increased from $2 / 3$ to $4 / 5$ ). Those who preferred the risky job in the first stage got a new risky alternative with a lower $\lambda$ (it fell from $2 / 3$ to $1 / 2$ ). Based on the choices made, and excluding risk loving attitudes, each agent can be classified with a $\lambda$ in one of four intervals: $[0,1 / 2],(1 / 2,2 / 3],(2 / 3,4 / 5],(4 / 5,1]$ These intervals have a natural ordering from "weakly risk averse" to "very risk averse".

It turns out that a high fraction (44\%) of the respondents end up in the last interval. In the analysis I use a high risk aversion dummy ("High-risk") taking the value 1 if a respondent make choices consistent with a $\lambda \in(3 / 4,1]$ and 0 otherwise.

\section{Workplace productivity}

The data contains weekly data on individual productivity, sales, answered phones, logon time etc., from 2003 until 2011. If agents want a bonus that maximizes their income it is their current (future) relative productivity (above or below the team average) that matters for their preferred payment scheme. The problem with using a snapshot of production just around the survey dates, is that the assessment of individual productivity gets clouded with measurement errors. As a compromise I use sales data from three quarters (39 weeks) prior to the surveys to construct a measure of relative productivity.

The measure is constructed by summing the difference between each worker's weekly sales and the mean sales of all other team members. The variable Diff-sales aggregates this difference in sales over all the relevant weeks: Diff-sales $=\sum_{t=2}^{39}\left(s_{i, j, t}-\bar{s}_{-i, j, t}\right)$, where $s_{i, j, t}$ is the number of sold insurance products for worker $i$, who belongs to team $j$, in week $t$ and $\bar{s}_{-i, j, t}$ is the average sales if $i$ is not included. This formula adjusts for seasonal variations in sales. ${ }^{10}$ If an agent was absent from work in "good" weeks we would underestimate this agent's true relative productivity if we first aggregated individual sales over the 39 weeks, and then took the difference.

Altogether there are 197 observations based on data from 131 individuals. Figure 2,

\footnotetext{
${ }^{10}$ Workers rarely change teams in this call centre. But in the beginning of 2009 two new teams were formed, they recruited some of their members from existing teams. Hence, to get a unique team identification for each worker I use data after week 13 (after first quarter) in 2009.
} 


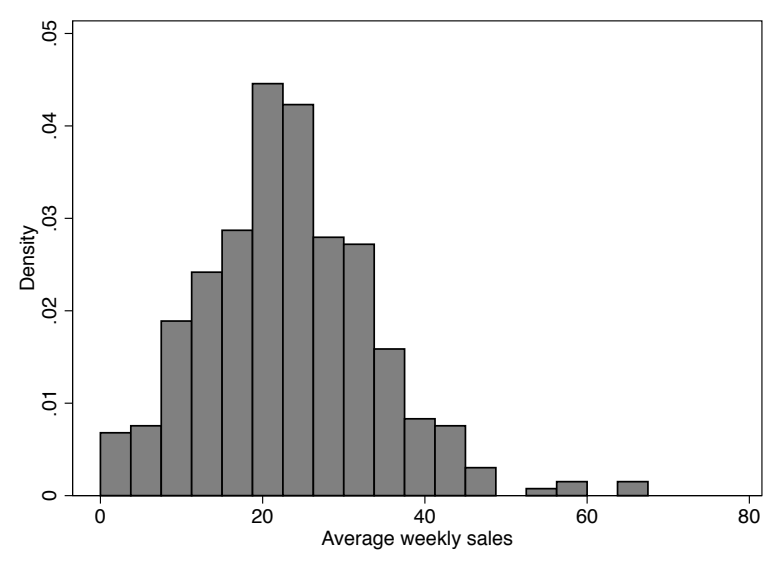

(a) The distribution of weekly sales

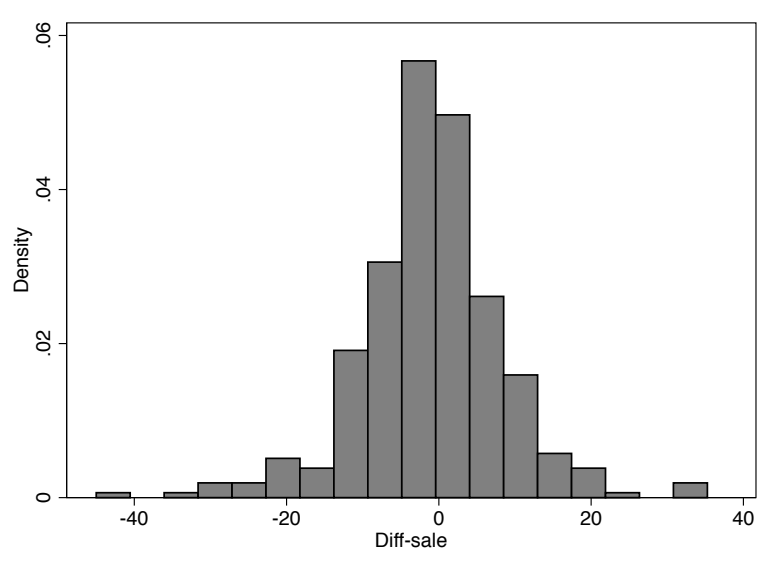

(b) The distribution of difference between individual sales and team average

Figure 2. The distribution of sales and Diff-sales

panel (a) plots the distribution of average weekly sales for the relevant period for all the observations included in this study. Panel (b) depicts the distribution of Diff-sales .

The sales and Diff-sales in Figure 2 are based on weeks where agents have been logged on the phone system at least 20 hours (a normal week expects an agent to be logged on the system for 35.5 hours in a week). By dropping weeks when agents are taken away from the phone system by the employer (to participate in training etc.) and weeks when agents are away due to vacation or periods of sickness absence, I get a cleaner measure of their sales productivity. ${ }^{11}$

Table 1 compares the mean and standard errors (in brackets below) for the pooled data for respondents and for the non-respondents. There is a significant difference in the average weekly sales between responders and non-responders; this difference is significant with a $p$ value of 0.07 with robust standard errors (clustered on agents).

\footnotetext{
${ }^{11} \mathrm{I}$ have done the same analysis without this restriction and the results are basically the same.
} 
Table 1. Differences between respondents and non-respondents

\begin{tabular}{lccc}
\hline Variable & Resp. $(\mathrm{N}=197)$ & Non-resp. $(\mathrm{N}=164)$ & Difference \\
\hline \multirow{2}{*}{ Sale } & 27.11 & 24.47 & $2.64(\mathrm{p}=.067)$ \\
& $(12.17)$ & $(11,38)$ & \\
Male & 0.40 & 0.43 & $-0.03(\mathrm{p}=.60)$ \\
& $(0.49)$ & $(0.49)$ & \\
Age-group & 5.41 & 5.65 & $-0.24(\mathrm{p}=.22)$ \\
& $(1.75)$ & $(1.73)$ & \\
Tenure years & 3.41 & 3.74 & $-0.33(\mathrm{p}=.36)$ \\
& $(1.99)$ & $(2.07)$ & \\
\hline
\end{tabular}

Note: The variable Age-group is equal to 1 if the person was born before 1955; 2 if birth date is in the interval "1956-1961"; 3 if birth date is in the interval "1961-1965" etc.

\section{Results}

Table 2 show how sales, risk-aversion, relative sales and the gender composition varies across the preferred bonus design. Those who prefer individual bonuses sell considerably more than their team mates, while those preferring a team based bonus scheme are - on average - below average. Those preferring individual pay also tend to be less risk averse than those who want team pay. The table also indicates that men favor a bonus based on individual performance. I have examined many other variables that one might expect to vary with preferred bonus scheme (for example type of education (economics or not), tenure, etc.) but there were no interesting patterns. 
Table 2. Bonus preferences, sales and risk aversion

\begin{tabular}{|c|c|c|c|c|c|}
\hline Bonus preferences & obs & Sale & Diff-sale & High-risk & Male \\
\hline Strong team pref & 15 & $\begin{array}{c}29.76 \\
(12.03)\end{array}$ & $\begin{array}{c}-1.85 \\
(12.70)\end{array}$ & $\begin{array}{c}0.66 \\
(0.49)\end{array}$ & $\begin{array}{c}0.20 \\
(0.40)\end{array}$ \\
\hline Team pref & 44 & $\begin{array}{l}20.90 \\
(8.70)\end{array}$ & $\begin{array}{l}-6.34 \\
(6.81)\end{array}$ & $\begin{array}{c}0.47 \\
(0.50)\end{array}$ & $\begin{array}{c}0.45 \\
(0.50)\end{array}$ \\
\hline Neutral pref & 29 & $\begin{array}{l}26.34 \\
(8.68)\end{array}$ & $\begin{array}{l}-0.14 \\
(6.41)\end{array}$ & $\begin{array}{c}0.57 \\
(0.50)\end{array}$ & $\begin{array}{c}0.36 \\
(0.49)\end{array}$ \\
\hline Individual pref & 75 & $\begin{array}{c}27.71 \\
(12.01)\end{array}$ & $\begin{array}{c}0.82 \\
(7.96)\end{array}$ & $\begin{array}{c}0.37 \\
(0.48)\end{array}$ & $\begin{array}{c}0.43 \\
(0.49)\end{array}$ \\
\hline Strong individual pref & 34 & $\begin{array}{c}33.00 \\
(17.28)\end{array}$ & $\begin{array}{c}7.44 \\
(12.52)\end{array}$ & $\begin{array}{c}0.38 \\
(0.49)\end{array}$ & $\begin{array}{c}0.58 \\
(0.50)\end{array}$ \\
\hline
\end{tabular}

Note: Standard deviations in parenthesis. High-risk measures the fraction of agents that are highly risk averse $(\lambda \geqq 4 / 5)$

Table 3 reports the results from regressing bonus preferences on relative productivity, risk attitudes and gender. The dependent variable (forind) is a numerical representation of the stated bonus preferences, it is equal to 1 if the agent is strongly in favour of team bonus and equal to 5 if the agent is strongly in favour of an individual bonus. I estimate a linear model (OLS) and an ordered logit model (OLOGIT). Both reveal the same pattern; the preference for individual bonuses increases with the difference between own sales and the team average and decreases with the risk aversion these agents reveal in the income gamble. Note that when we account for sales and risk aversion the gender effect vanishes.

I have also estimated an OLS model with individual fixed effects, using only within agent variation in relative productivity and reported risk attitudes over time to estimate how these variables impact on bonus preferences. In this model it is tempting to interpret the Diff-sale variable as causal; controlling for unobservable heterogeneity in individual "ideologies" (assuming that ideology is fixed over time) we observe that an improvement in relative productivity makes agents more inclined to prefer individual pay. 
Table 3. Bonus preferences, risk aversion and productivity

\begin{tabular}{|c|c|c|c|c|c|c|}
\hline & OLS & OLS & OLS(FE) & OLS (FE) & OLOGIT & OLOGIT \\
\hline Diff-sale & $\begin{array}{l}0.050^{* * *} \\
(0.010)\end{array}$ & $\begin{array}{l}0.050^{* * *} \\
(0.009)\end{array}$ & $\begin{array}{c}0.025^{* *} \\
(0.011)\end{array}$ & $\begin{array}{l}0.029^{* * *} \\
(0.009)\end{array}$ & $\begin{array}{l}0.100^{* * *} \\
(0.019)\end{array}$ & $\begin{array}{l}0.101^{* * *} \\
(0.019)\end{array}$ \\
\hline High-risk & $\begin{array}{l}-0.278 \\
(0.175)\end{array}$ & $\begin{array}{l}-0.373^{* *} \\
(0.174)\end{array}$ & $\begin{array}{c}0.049 \\
(0.229)\end{array}$ & $\begin{array}{l}-0.095 \\
(0.255)\end{array}$ & $\begin{array}{c}-0.529^{*} \\
(0.292)\end{array}$ & $\begin{array}{l}-0.674^{* *} \\
(0.295)\end{array}$ \\
\hline Male & $\begin{array}{c}0.349^{* *} \\
(0.176)\end{array}$ & $\begin{array}{c}0.346^{* *} \\
(0.174)\end{array}$ & & & $\begin{array}{c}0.543^{*} \\
(0.302)\end{array}$ & $\begin{array}{c}0.553^{*} \\
(0.306)\end{array}$ \\
\hline 2009 & & $\begin{array}{c}0.434^{* *} \\
(0.193)\end{array}$ & & $\begin{array}{c}0.433^{*} \\
(0.186)\end{array}$ & & $\begin{array}{l}0.619^{* *} \\
(0.304)\end{array}$ \\
\hline 2010 & & $\begin{array}{c}0.321^{*} \\
(0.184)\end{array}$ & & $\begin{array}{c}0.366 \\
(0.240)\end{array}$ & & $\begin{array}{c}0.502 \\
(0.308)\end{array}$ \\
\hline obs & 197 & 197 & 197 & 197 & 197 & 197 \\
\hline R-squared & 0.199 & 0.219 & 0.151 & 0.178 & 0.193 & 0.209 \\
\hline
\end{tabular}

Note: The dependent variable is forind, which is equal to 1 if the agent is strongly in favour of team bonus and 5 if the agent is strongly in favour of an individual bonus. Standard errors in parentheses (robust and clustered on individual agents).

$* p<0.1, * * p<0.05, * * * p<0.01$

The results in Table 3 are in accordance with the predictions from the standard Principal-Agent model. It is possible to check more directly, and in more detail, whether the inclination to vote for the bonus that furthers ones own income depends on being above or below the average. In Table 4 those who report a strong or weak preference for an individual bonus are characterized as "Individual", those who express no preference for either a team or individual bonus are "Neutral" and those who are either weakly or strongly in favour of a group based bonus are in the "Team" category. 
Table 4. Bonus preferences and relative productivity

\begin{tabular}{lccccccc} 
& \multicolumn{3}{c}{ Above average } & & \multicolumn{3}{c}{ Below average } \\
\cline { 2 - 4 } \cline { 7 - 8 } Individual & $65(76 \%)$ & $28(74 \%)$ & $37(78 \%)$ & & $44(39 \%)$ & $25(52 \%)$ & $19(30 \%)$ \\
\cline { 8 - 9 } Neutral & $12(14 \%)$ & $6(16 \%)$ & $6(13 \%)$ & & $17((15 \%)$ & $5(10 \%)$ & $12(18 \%)$ \\
Team & $8(10 \%)$ & $4(10 \%)$ & $4(9 \%)$ & & $51(46 \%)$ & $18(38 \%)$ & $33((52 \%)$ \\
obs. & 85 & 38 & 47 & & 112 & 48 & 64 \\
\hline
\end{tabular}

In Table 4 a high fraction of the agents performing below average prefer an individual bonus. These agents prefer a payment scheme providing less insurance and lower income than an available alternative. This pattern is especially pronounced among men. The gender difference is statistically significant. Table 5 reports the results from regressing individual on an indicator that takes the value 1 if a person performs below average (below) and an interaction between this variable and the indicator for being a male. Being below average reduces the probability of preferring an individual bonus, but significantly less so for males than for females.

Table 5. Low productivity and the preference for an individual bonus

\begin{tabular}{lcc}
\hline & LPM & PROBIT \\
\hline Male & -0.05 & -0.16 \\
& $(0.10)$ & $(0.32)$ \\
Below & $-0.49^{* * *}$ & $-1.33^{* * *}$ \\
& $(0.08)$ & $(0.26)$ \\
& & \\
Below*Male & $0.27^{* *}$ & $0.74^{*}$ \\
& $(0.13)$ & $(0.39)$ \\
Constant & $0.78^{* * *}$ & $0.79^{* * *}$ \\
& $(0.06)$ & $(0.21)$ \\
& & \\
obs. & 197 & 197 \\
R-squared & 0.16 & 0.13 \\
\hline
\end{tabular}

Note: The dependent variable ind is an indicator variable equal to 1 if the agent prefers an individual bonus, and 0 otherwise. Standard errors in parentheses (robust and clustered on individual agents).

$* p<0.1, * * p<0.05, * * * p<0.01$ 


\section{Why do low productivity agents prefer individual bonuses?}

One possible answer is that with a team-bonus low productivity workers are paid above their productivity and this may increase their risk of being fired, and men may care more about this risk than women. ${ }^{12} \mathrm{I}$ do not think this explanation is relevant for the case studied here; in Norway it is impossible to fire workers because they have low relative productivity. In this firm - for as long as I have data (8 years) - there is not a single case where a customer service agent has been fired. Below, I discuss several alternative explanations.

\section{Confusion}

Maybe workers do not know their own relative productivity? Imprecise knowledge about own relative productivity coupled with the observation that men tend to be overconfident about their own abilities could explain the pattern in the data (Niederle and Vesterlund (2007)). The problem with this explanation is that the customer service agents in this company know a lot about their own relative productivity. They keep a record of their own sales and at the beginning of each week the team leader informs them about the average team sales and how they are doing compared to their budget etc. It is nevertheless perceivable that those who are close to the team average are not fully aware whether they are above or below the mean. If that is the explanation we should expect that it is especially low productivity agents who are just below the average who prefer individual pay. That is not the case. The average Diff-sale for observations below average $($ Diff-sale $<0)$ is $-6,4$. The average Diff-sale for those who produce below average and vote for individual bonuses is $\mathbf{- 5 . 8}$, this difference is not significant at any conventional significance levels.

\section{Poum}

Another possibility is that some workers with low productivity expect to excel and

\footnotetext{
${ }^{12}$ I thank the editor for pointing out this possibility.
} 
produce above average in the future, that is why they prefer individual pay. They vote against a redistributive scheme (team pay), because they have "prospect of upward mobility" (POUM) (Benabou and Ok (2001)). It is reasonable to base expectations about relative future performance on the current trend in relative productivity. Hence, if the prospect of upward mobility explains why low achievers prefer individual bonuses, we should expect these agents to be on a steeper sales trend than their team mates. To check this possibility I estimate

$$
\operatorname{Diff}-\text { sale }_{i t}=\alpha_{i}+\beta t+\gamma t * \text { lowind }+\varepsilon_{i t},
$$

where $\alpha$ captures individual fixed effect on relative sales, $t$ is the number of weeks that passes from the start of the year until the date when the workers answered the questionnaire, and lowind is an indicator variable that is equal to 1 for agents who have a low productivity (below team average) and who prefer an individual bonus, $\varepsilon_{i t}$ is the error term. Pooling the data over all years, the OLS estimates are $\hat{\beta}=-0.04(0.07)$ and $\hat{\gamma}=-0.01(0.16)$; there is no indication that lowind agents are on a steeper productivity trend than the rest of their team.

\section{Reversed causality}

I have been careful in asserting causality. It is nevertheless tempting to think that relative productivity affects the preferred bonus scheme. But there could also be a force going in the other direction; bonus preferences could influence observed productivity. At the time of the surveys, in the fall of 2007, 2009 and 2010, the bonus was based both on individual and team performance. But, as Figure 1 depicts, the maximal individual bonus is twice as high as the team bonus. Despite this, it could be that some agents, with a very strong taste for individual pay, found it demotivating to work under a team based bonus. In the data, they appear with below average sales and with a strong preference for an individual bonus.

The data can be used to examine the relevance of this explanation. In October 2006 the bonus scheme underwent a major reform. The power of the sales incentives increased 
(more than doubled) and the bonus was completely individualized. This design lasted for six months. In April 2007 the firm reinstalled to the hybrid version with the bonus depending both on individual sales and team sales.

If lowind workers find it especially uninspiring to work under a team bonus they ought to increase their sales particularly much in the period when incentives are individualized. This possibility can be checked by comparing sales during the reform period (when the bonus was based on individual sales) with sales in the 6 months prior to the reform. To check this I estimate

$$
\text { sales }_{i t}=\alpha_{i}+\beta r e f+\gamma r e f * \text { lowind }+ \text { calls }+\varepsilon_{i t},
$$

where $\alpha_{i}$ is individual fixed effects and the variable $r e f$ is an indicator variable equal to 1 in the period when the sales bonus was individualized and lowind is, as above, an indicator for agents who prefer an individual bonus even though they sell less than the average in the team, calls are incoming calls. The parameter of interest $\gamma$ captures how the lowind group responds to the individualization of the sales bonus compared to how the rest of the workers respond to this reform.

Estimating (2) gives a positive reform effect $\hat{\beta}=2.07(0.53)$, but no indication that those in the lowind group increased their effort more than the rest of the workers, $\hat{\gamma}=$ $-1.23(1.45){ }^{13}$

\section{Social motivation}

None of the explanations above are consistent with the data. It is therefore natural to consider the social motivations discussed in the theoretical backdrop. Note first that inequity aversion hypothesis formulated in Fehr and Schmidt (1999) is not consistent with the data. Inequity aversion can explain why some of the high achievers prefer a team bonus, but it cannot account for the fact that it is mainly among low performers we

\footnotetext{
${ }^{13}$ Robust standard errors in the brackets. A drawback with using a reform in 2006 to check the "reverse causality hypothesis" is that many of the workers who responded to the 2009 and 2010 surveys were not employed in the company at that time. The estimates are based on data from 151 agents, 15 of these agents belong to the lowind group (that is, 15 of the lowind group are present both before and after the 2006 pay reform).
} 
find workers who prefer a bonus scheme that oppose their economic interests.

Recall that low productivity workers with a meritocratic fairness principle face a real trade-off: By choosing a team bonus they earn more money but such a choice violate their fairness ideal. If such a worker is sufficiently fair minded, that is, if he experiences a sufficiently high utility loss by deviating from the "pay according to production" principle, he will go for an individual bonus. Another social motivation that may induce workers with a low productivity to vote for individual pay is the self regarding desire to avoid negative social appraisal, peer pressure and ostracism. A team bonus put a lot of internal and external pressure on low productivity workers and to rid themselves from this distress they may prefer individual pay, even if such a bonus lowers their income.

To scrutinize and separate the meritocratic fairness explanation from the social appraisal explanation I use the fact that it seems reasonable that for the fairness argument the whole distribution of bonuses and productivity within a team matters, while the social appraisal concern is based only on the difference between own productivity and the team average. Hence if low productivity agents vote for an individual bonus mainly because they adhere (strongly) to a meritocratic fairness standards, we should expect this preference to be overrepresented in teams with a high variance in productivity. ${ }^{14}$

To check this, I regress the probability of being a lowind agent on the standard deviation $(s t d v)$ of sales within the team that the agent belongs. The standard deviation in sales is the average standard deviation in sales over the weeks leading up to the surveys. I have estimated both a linear probability model and a probit model and in none of these models does the standard deviation in sales within the team (stdv) increase the probability of belonging to the lowind group.

\footnotetext{
${ }^{14}$ Agents cannot sort into different teams at this workplace. When hired, after a short trial period, a person is allocated to a team that needs more personnel (because someone has left the customer service centre) and they stay in that team as long as they work as call centre agents.
} 
Table 6. Heterogeneity in productivity within teams and agents preferences for individual pay

\begin{tabular}{lcc}
\hline & LPM & Probit \\
\hline Diff-sale & $-0.013^{* * *}$ & $-0.072^{* * *}$ \\
& $(0.002)$ & $(0.017)$ \\
stdv & -0.008 & $-0.052^{* *}$ \\
& $(0.006)$ & 0.024 \\
constant & $0.330^{* *}$ & -0.257 \\
& $(0.089)$ & $(0.312)$ \\
obs. & 197 & 197 \\
R-squared & 0.14 & 0.14 \\
\hline
\end{tabular}

Note: The dependent variable lowind is an indicator variable equal to 1 if the agent is below average in productivity and prefers an individual bonus, 0 otherwise. Standard errors in parentheses (robust and clustered on individual agents).

$* p<0.1, * * p<0.05, * * * p<0.01$

In fact $s d t v$ has a negative but insignificant impact on lowind. This result suggests that low productivity agents prefer individual pay to rid themselves from peer pressure and negative social appraisal.

\section{Conclusion}

Do workers in teams prefer a bonus plan that maximizes their own income? I present data from one firm, showing that the broad answer is yes; workers tend to want a bonus that advance their own material interests. A more detailed examination of the data reveals a pattern that deviates from income maximization: A substantial fraction of the workers who produce less than the team average prefer a bonus based on individual performance. Several explanations for this pattern is examined. The one that accords best with the data is that (some) low productivity workers prefer individual pay to avoid peer pressure and negative social appraisal.

\section{References}

Aarbu, K. and F. Schroyen (2009). Mapping risk aversion in norway using hypothetical income gambles. NHH Dept. of Economics Discussion Paper (13). 
Aksin, Z., M. Armony, and V. Mehrotra (2007). The modern call center: A multidisciplinary perspective on operations management research. Production and Operations Management 16(6), 665-688.

Babcock, P., K. Bedard, G. Charness, J. Hartman, and H. Royer (2011). Letting down the team? evidence of social effects of team incentives. Technical report, National Bureau of Economic Research.

Bandiera, O., I. Barankay, and I. Rasul (2005). Social preferences and the response to incentives: Evidence from personnel data. The Quarterly Journal of Economics 120(3), $917-962$.

Barsky, R. B., F. T. Juster, M. S. Kimball, and M. D. Shapiro (1997). Preference parameters and behavioral heterogeneity: An experimental approach in the health and retirement study. The Quarterly Journal of Economics 112(2), 537-579.

Benabou, R. and E. A. Ok (2001). Social mobility and the demand for redistribution: the poum hypothesis. The Quarterly Journal of Economics 116(2), 447-487.

Bolton, G. E. and A. Ockenfels (2000). Erc: A theory of equity, reciprocity, and competition. American economic review, 166-193.

Camerer, C. (2003). Behavioral game theory: Experiments in strategic interaction. Princeton University Press.

Cappelen, A. W., A. D. Hole, E. Ø. Sørensen, and B. Tungodden (2007). The pluralism of fairness ideals: An experimental approach. American Economic Review 97(3), 818-827.

Charness, G. and M. Rabin (2002). Understanding social preferences with simple tests. The Quarterly Journal of Economics 117(3), 817-869.

Cooper, D. and J. H. Kagel (2009). Other regarding preferences: a selective survey of experimental results. Handbook of experimental economics 2.

Dohmen, T. and A. Falk (2011). Performance pay and multidimensional sorting: Productivity, preferences, and gender. The American Economic Review 101(2), 556-590. 
Dur, R. and J. Sol (2010). Social interaction, co-worker altruism, and incentives. Games and Economic Behavior 69(2), 293-301.

Englmaier, F. and A. Wambach (2010). Optimal incentive contracts under inequity aversion. Games and Economic Behavior 69(2), 312-328.

Esarey, J., T. Salmon, and C. Barrilleaux (2012). Social insurance and income redistribution in a laboratory experiment. Political Research Quarterly 65(3), 685-698.

Fehr, E. and K. M. Schmidt (1999). A theory of fairness, competition, and cooperation. The quarterly journal of economics 114(3), 817-868.

Fershtman, C., U. Gneezy, and J. A. List (2012). Equity aversion: Social norms and the desire to be ahead. American Economic Journal-Microeconomics 4(4), 131.

Hamilton, B. H., J. A. Nickerson, and H. Owan (2003). Team incentives and worker heterogeneity: An empirical analysis of the impact of teams on productivity and participation. Journal of political Economy 111(3), 465-497.

Hansen, D. G. (1997). Worker performance and group incentives: A case study. Indus. \& Lab. Rel. Rev. 51, 37.

Itoh, H. (2004). Moral hazard and other-regarding preferences. Japanese Economic Review $55(1), 18-45$.

Kandel, E. and E. P. Lazear (1992). Peer pressure and partnerships. Journal of political Economy, 801-817.

Konow, J. (2003). Which is the fairest one of all? a positive analysis of justice theories. Journal of economic literature 41(4), 1188-1239.

Kuhn, P. and M. C. Villeval (2015). Are women more attracted to cooperation than men? The Economic Journal 125, 115-140.

List, J. A. and I. Rasul (2011). Field experiments in labor economics. Handbook of labor economics 4, 103-228. 
Mas, A. and E. Moretti (2009). Peers at work. The American Economic Review 99(1), $112-145$.

Niederle, M. and L. Vesterlund (2007). Do women shy away from competition? do men compete too much? The Quarterly Journal of Economics, 1067-1101.

Rey-Biel, P. (2008). Inequity aversion and team incentives. The Scandinavian Journal of Economics 110(2), 297-320.

Weiss (1987). Incentives and worker behavior: Some evidence. Technical report, NBER working paper No. 2194. 